\title{
Analysis of production planning activities in remanufacturing system
}

\section{Andrew-Munot ${ }^{1 *}$, A. Yassin ${ }^{1}$, S. T. Syed Shazali ${ }^{1}$, M. Sawawi ${ }^{1}$, S. J. Tanjong ${ }^{1}$, N. Razali $^{1}$}

${ }^{1}$ Faculty of Engineering, Universiti Malaysia Sarawak, 94300 Kota Samarahan, Sarawak, Malaysia

"Email: ammagdal@unimas.my

Phone: +6082583300; Fax: +6082583410

\begin{abstract}
This article examines the problem of uncertain quantities and quality conditions of used-products obtained from the customer-stream, third-party-stream \& mixed-stream on remanufacturing cycle-time under three different remanufacturing resources policies. Simulation technique is used to model a remanufacturing system with uncertain quantities and quality conditions of used-products obtained from the customer-stream, third-party-stream and mixed-stream under three different remanufacturing resource policies. Findings show that the quantities of used-products either from the customer-stream or third-party-stream affect the remanufacturing cycle-time. For used-products form the mixed-stream, the percentage of used-products from the customer-stream greatly affects the remanufacturing cycle-time. The different remanufacturing resource policies also affect the remanufacturing cycle-time. It can be established and concluded that the performance of a remanufacturing system is affected by the uncertain quantities and quality conditions of used-products.
\end{abstract}

Keywords: used-products; remanufacturing; production planning; simulation.

\section{INTRODUCTION}

Nowadays, used-products remanufacturing has become an important part of normal production activity in many companies. Some examples of remanufactured products are automotive parts [1, 2], agricultural machinery [3], PC tablets [4], photocopiers [5] and smartphones [6]. Remanufacturing aims to transform used-products or some of the components into a like-new condition. The process typically includes inspection \& grading, disassembly, component reprocessing/replacement and reassembly \& testing [7]

The performance of remanufacturing system is very crucial for surviving the competitive remanufacturing industry [2]; this requires optimize cooperation of the remanufacturing process steps [8].

In remanufacturing environment, there are several unique characteristics that further complicate the production planning and control activities [9-11]. These characteristics are (i) uncertain quality conditions of incoming used-products which are due to their different degree of usage, (ii) uncertain quantities of used products available for remanufacture, (iii) uncertain inspection yield of the used-products, (iv) uncertain disassembly yield of the disassembled components, (v) uncertain reprocessing effort of the disassembled constituent components, (vi) multiple types of constituents components, (vii) match and reassemble the same set of constituent components into a final product, (viii) balancing customer demand and supply of used-products. 
The existence of these unique characteristics and their interactions present greater challenges to production planning and control activities in remanufacturing companies. It is imperative that these unique characteristics are treated as a set of criteria in the modelling and analysis of remanufacturing systems [7, 12, 13]. Also, it is important to consider these all unique characteristics in an integrated approach to study remanufacturing in order to achieve efficient and effective systems [14-18]. Many researchers have studied problems related to unique characteristics mentioned above. Our work is related to literatures on uncertain quantities and quality conditions of used-products, which are briefly reviewed below.

Teunter and Flapper [19] studied the optimal acquisition decisions under multiple quality classes and a multinomial quality distribution for an acquired lot; they proposed a model that incorporate uncertain used-products quality fractions in the decision-making. Jin et. al. [20] investigated the optimal policy for modular product reassembly in a remanufacturing firm that receives used-products of variable quality conditions. Karamouzian et. al. [21] developed an admission control policy for accepting used-products for remanufacture under variable quality conditions of incoming used-products. Iwao and Kusukawa [22] examined production planning problem in the presence of uncertain quality conditions of used-products and error in quality grading.

Tao et. al. [23] examined the ordering/remanufacturing policy that captures uncertainty in the remanufacturing yield, which is caused by uncertain quality conditions of used-products. Mezghani and Loukil [24] proposed an aggregate production planning model for remanufacturing in the presence of different and imprecise quality levels of used-products. Robotis et. al. [25] studied the impact of uncertain quality conditions on the reusability investment and collection of used-products in a hybrid manufacturing/remanufacturing system. Zikopoulos [26] investigated the implications of having complete/incomplete information of quality conditions of used-product on remanufacturing planning and inventory control. This effects of complete/incomplete information of quality conditions of used-products on planning and inventory control were studied using mathematical expressions. Jin et. al. [27] studied the optimal policy for modular product reassembly for reassembling multiple classes of products under variable quality conditions of used-products.

Karamouzian et. al. [28] proposed a grading based acquisition policy for determining used-products to be remanufactured and scrapped. Wei et. al. [29] examined the refund policy and profit maximization problem that consider variable quality conditions of used-products. Alqahtani et. al. [30] studied the effect of sensor embedded products and RFID tags on performance of advance remanufacture-to-order reassembly-to-order and refurbishment-to-order system. Yanga et. al. [31] studied acquisition problem in the presence of variable quality conditions of used-products; specifically the effect of quality distributions, cost relationships of acquirable cores and remanufacturing cost function on the total cost. Mashhadi et. al. [32] examined the problem of take-back and inventory planning under uncertain quantities \& quality of used-product and demand for remanufactured products.

Li et. al. [33] investigated acquisition and remanufacturing decisions in the presence of variable quality conditions of used-products under various sorting strategies for remanufacture-to-stock (RMTS) and remanufacture-to-order (RMTO). Mutha et. al. [34] examined acquisition strategies for a third party remanufacturer which include (i) whether to purchase used-products in bulk with uncertain quality levels, (ii) or in sorted grades with known quality levels, (iii) whether to purchase and remanufacture used-products before the demand is realized (planned acquisition), or after the demand is 
realized (reactive acquisition), or on both occasions (sequential acquisition). Yang et. al. [35] examined acquisition problem considering quantity discount and carbon tax scheme under variable and uncertain quality conditions of used-products. In another work, Yang et. al. [36] considered acquisition problem for multiple type of used-products with highly variable quality conditions under independent demand and carbon emission regulation. Zikopoulos [11] studied the impacts of uncertain remanufacturing processing time (due to variable quality conditions) on production planning and inventory management decision.

Aydin et. al. [37] proposed a mathematically based methodology for determining the optimal quantity of used-products for remanufacture in the presence of uncertain quality level and quantities of used-products. Oh and Behdad [6] examined reassembly and acquisition problems in a reassemble-to-order remanufacturing system that accepts highly uncertain quantities of used-products from the waste stream. Gavidel and Rickli [38] proposed a product-state-transformation-diagram based model for analyzing the quality of used-products under uncertain age and usage conditions. In another work Gavidel and Rickli [39] investigated the joint effects of used-products quality conditions, quantities, and timing on remanufacturing cost under normal and extreme return conditions. Zhou et. al. [40] analysed the effect of quality uncertainty on carbon emissions while examining acquisition and remanufacturing policies problem of an independent remanufacturing system.

For the majority of research above, the problems were studied and solutions were proposed mathematically. Given that remanufacturing environment is complicated by the presence of unique characteristics, then study on the effects of these unique characteristics would significantly benefit from the application of simulation technique. Simulation technique is widely used in modelling and analysis of many decision-making models for manufacturing. This wide application is due to its superior analysis capability that provides analyst with a system-wide view of the effect of changes in system parameters on the system's performance [41-43]. However, for remanufacturing there is limited work that apply simulation technique; examples could be found in [30, 31].

Most of the research above did not study problems related to used-products source, which are either from the customer-stream or third-party-stream. Given that the quantities and quality conditions of used-products are uncertain, then acquisitions have to consider both streams to meet demand for remanufactured product. Consequently, acquisition decisions in the presence of uncertain quantities and quality conditions of used-products either from the customer-stream and/or third-party stream would affect remanufacturing resource allocation decision. Therefore, the research gap is the application of simulation technique to study the effects of uncertain used-products quantities acquired from the customer, third-party and mixed stream on the performance of remanufacturing system under different remanufacturing resource polices.

Then, the research questions are (i) what are the effects of used-products quantities from the customer, third-party \& mixed-stream on remanufacturing performance, (ii) what is the used-products mix required to achieve high remanufacturing performance, (iii) what is the best remanufacturing resource policy to achieve high remanufacturing performance.

Thus, the motivation of this current work is to study a remanufacturing system that receives used-products of uncertain quantities and quality conditions either from the customer, third-party \& mixed stream and process these according one of the three different resource policies. The objectives of this work are (i) to analyse the effects of customer-stream used-products quantities, third-party-stream used-products quantities \& 
mixed-stream used-products quantities on the remanufacturing cycle time, (ii) to analyse and compare the different remanufacturing resource policies. This article is organised as follows. In section 2, the problem descriptions are presented, in section 3 the methodology is described, section 4 presents and discusses the results and conclusion is provided in section 5 .

\section{PROBLEMS DESCRIPTION}

This article considers a remanufacturing system with the following characteristics. Used-products with uncertain quantities and quality conditions are sourced either from the third-party collection center or directly from customers who trade in their used-products with new or remanufactured products. Given the uncertain quantities and quality conditions of used-products, then it would be necessary to acquire used-products from both streams to guarantee continuous production. The uncertain quantities of used-products are modeled in terms of uncertain inter-arrival times of used-products arriving at the remanufacturing system.

Ultimately, it is important to determine the best resource policy for processing these used-products from both streams to achieve short remanufacturing cycle-time. Three different resource policies considered are (i) one resource is available for remanufacturing where used-products from customers, third-party and mixed streams are processed based on a first-come-first-serve priority (Policy 1), (ii) two resources are available for remanufacturing where used-products from customer, third-party and mixed streams are processed in either one of these two resources (switching is allowed), based on a first-come-first-serve priority (Policy 2), (iii) two resources are available for remanufacturing; each resource is dedicated to process the specified stream of customer (switching is not allowed), third-party or mixed streams (Policy 3). Unlike previous research, these problems are studied and analyze using simulation technique.

\section{METHODOLOGY}

\section{Model development}

Figure 1 shows the conceptual model of a remanufacturing system with four processes, namely inspection \& sorting, disassembly \& inspection, components reprocessing and reassembly \& testing. Used-products obtain either from the customer or third-party stream are inspected \& sorted in the first process. Those used-products that are beyond remanufacturable conditions are scrap off and those that are within remanufacturable conditions are stored in inventory waiting for the next process. Next remanufacturables used-products are disassembled completely into their corresponding constituent components; any components that are beyond repair are scrap off and replacement components are ordered. The rest of the components are repaired/restored to as good as new condition. Finally, the repaired components are reassembled together with any replacement components to make remanufactured products. Remanufactured products are then stored in serviceable inventory waiting for customers' demand.

The conceptual model is already established in previous work [7] and adopted in the current work. This conceptual model is translated into the corresponding simulation model, in which the computer programs are coded in the ARENA simulation platform [44]. The simulation model is verified using an animation technique recommended by Kelton et. al. [41] and Lari and Singh [42] to ensure the model's assumption are correctly coded into the computer programs. The simulation model is also validated using a 
qualitative technique implemented in [7] and sensitivity analysis suggested by Lari and Singh (2014) [42], to ensure the simulation model is an accurate representation of the remanufacturing system intended to achieve the objectives.

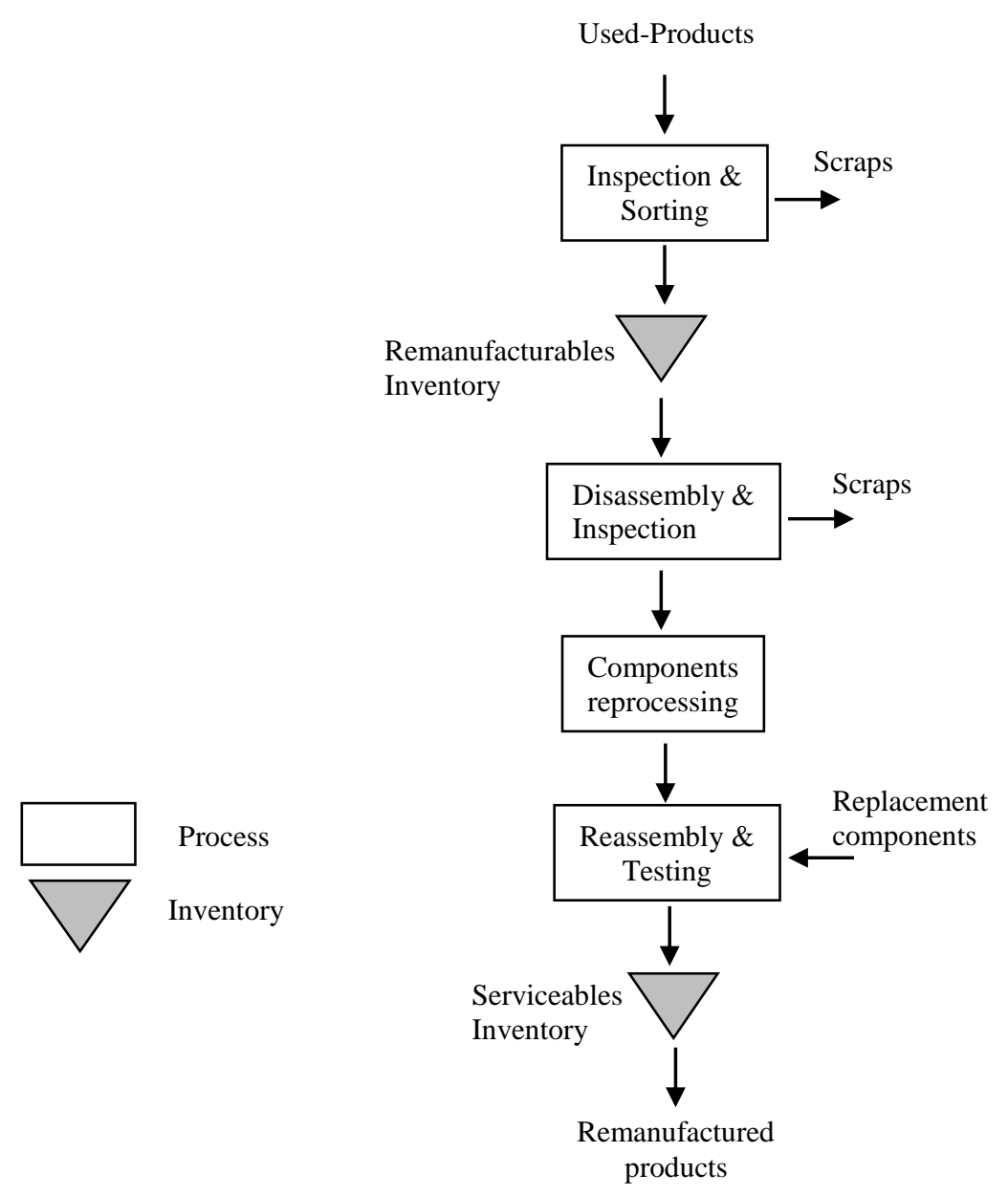

Figure 1. Generic conceptual model of a remanufacturing system [7]

\section{System variables and values}

Table 1 tabulates the system variables and their values implemented to achieve the objectives of this work. Used-products from the customers-stream are modelled to arrive one unit at a time with inter-arrival time according to an exponential (Expo) distribution; the exponential (Expo) distribution represents uncertain inter-arrival times (hence uncertain quantities available). The third-party-stream used-products are also modelled to arrive one unit at a time, but with inter-arrival times according to constant (Const) distribution; this distribution represent controllable or certain inter-arrival times [11] (hence certain quantities). The values for customers-stream used-products inter-arrival times are taken from work by Shah et al [45]. For the third-party-stream used-products with constant (Const) distribution the values for inter-arrival times are assumed to be similar to the customers-stream. For both customer and third-party stream used-products, five different values of inter-arrival times are considered for analyzing objective 1 and two different values are considered for analyzing objective 2 . 
Table 1. Remanufacturing system variables and their values

\begin{tabular}{|c|c|c|c|}
\hline System Variables & $\begin{array}{l}\text { Values for } \\
\text { analysis } 1\end{array}$ & $\begin{array}{l}\text { Values for } \\
\text { analysis } 2\end{array}$ & Notes \\
\hline $\begin{array}{l}\text { Customers-stream } \\
\text { used-products } \\
\text { inter-arrival times }\end{array}$ & $\begin{array}{l}\text { Expo (3) days, } \\
\text { Expo (4) days, } \\
\text { Expo (5) days, } \\
\text { Expo (6) days, } \\
\text { Expo (7) days }\end{array}$ & $\begin{array}{l}\text { Expo (3) days, } \\
\text { Expo (7) days }\end{array}$ & $\begin{array}{c}\text { Similar to study } \\
\text { by Shah et al., } \\
{[45]}\end{array}$ \\
\hline $\begin{array}{l}\text { Third-party-stream } \\
\text { used-products } \\
\text { inter-arrival times }\end{array}$ & $\begin{array}{l}\text { Const. (3) days, } \\
\text { Const. (4) days, } \\
\text { Const. (5) days, } \\
\text { Const. (6) days, } \\
\text { Const. (7) days }\end{array}$ & $\begin{array}{l}\text { Const. (3) days, } \\
\text { Const. (7) days }\end{array}$ & $\begin{array}{l}\text { Quantities and } \\
\text { quality } \\
\text { conditions are } \\
\text { controllable } \\
\text { compared to } \\
\text { customers } \\
\text { used-products } \\
\text { inter-arrival } \\
\text { times }\end{array}$ \\
\hline $\begin{array}{l}\text { Used-products mix } \\
\text { (percentage) }\end{array}$ & $\begin{array}{c}20 \% \mathrm{C}-80 \% \mathrm{~T}, \\
35 \% \mathrm{C}-65 \% \mathrm{~T} \\
50 \% \mathrm{C}-50 \% \mathrm{~T} \\
65 \% \mathrm{C}-35 \% \mathrm{~T} \\
80 \% \mathrm{C}-20 \% \mathrm{~T}\end{array}$ & $50 \% \mathrm{C}-50 \% \mathrm{~T}$ & \\
\hline $\begin{array}{l}\text { Overall repair time } \\
\text { for customers } \\
\text { used-products }\end{array}$ & Unif $(3,4)$ & $\begin{array}{l}\text { Unif }(3,4) \\
\text { Unif }(7,8)\end{array}$ & $\begin{array}{c}\text { Similar to study } \\
\text { by Shah et al., } \\
{[45]}\end{array}$ \\
\hline $\begin{array}{l}\text { Overall repair time } \\
\text { for third-party } \\
\text { used-products }\end{array}$ & Unif $(2,4)$ & Unif $(2,4)$ & $\begin{array}{l}\text { Better quality } \\
\text { conditions than } \\
\text { customers } \\
\text { used-products, } \\
\text { thus shorter } \\
\text { overall } \\
\text { remanufacturing } \\
\text { time [36] }\end{array}$ \\
\hline
\end{tabular}

Expo - exponential distribution

Const. - constant distribution

Unif. - uniform distribution

The mixed-stream represented combined used-products from the customers and third-party stream; for example, a value of $20 \% \mathrm{C}-80 \% \mathrm{~T}$ represents $20 \%$ of the used-products quantities are from the customers-stream and $80 \%$ of the used-products quantities are from the third-party-stream. Five different values of used-products mix are considered for analyzing objective 1 and one value is considered for analyzing objective 2. 
The overall repair time for customers-stream used-products is modelled according to Uniform (Unif) distribution; one value is considered for analyzing objective 1 and two different values are considered for analyzing objective 2; both distributions and values are similar to work by Shah et al [45]. For the third-party stream-used-products, the overall repair time is also modelled according to Uniform (Unif) distribution with one value for analyzing both objectives 1 and 2. Given that the quality conditions of third-party-stream used-product are better than the customers- stream used-products than the overall repair time value is assumed to be shorter time than the overall repair for customers-stream used-products [36]. Three different remanufacturing resource policies are analyzed and compared in objective 2 of this work. These three types of resource policies are commonly implemented in the manufacturing industry; thus it is fair to assumed that these types of resource policies could also be implemented in the remanufacturing industry.

\section{Simulation experiments}

The analyses for objective 1 considered four variables (customers-stream used-products inter-arrival times, third-party-stream used-products inter-arrival times, used-products mix and resource policy). The factorial design for analyzing the (i) effects of customers-stream used-products on remanufacturing cycle-time under three resource policies are 15 cases $\left(2^{5} \times 2^{3}\right)$; (ii) the effects of third-party-stream used-products on remanufacturing cycle-time under three resource policies are 15 cases $\left(2^{5} \times 2^{3}\right)$; (iii) the effects of used-products mixed on remanufacturing cycle-time under three resource polices are 15 cases $\left(2^{5} \times 2^{3}\right)$.

The analyses for objective 2 considered five variables (customers-stream used-products inter-arrival times, third-party-stream used-products inter-arrival times, used-products mix, customers-stream used-products overall repair times and resource policies). The factorial design for analyzing the different resource polices are 24 cases $\left(2^{2}\right.$ x $2^{2} \times 2^{3} \times 2^{2}$ ) for each Policy 1, 2, \& 3. Two different policies (Policy 2 versus Policy 1, Policy 3 versus Policy 1, Policy 3 versus Policy 2) are compared in terms of remanufacturing cycle-times using the ARENA output analyzer; this ensured that the differences in remanufacturing cycle-time are statistically significant. The simulation experiments for objectives $1 \& 2$ are ran using a warm-up period of 20000 hours, replication length of 480 hours and replication number of 100.

\section{RESULTS AND DISCUSSIONS}

Simulation experiments are carried out to achieve the objectives of this work. It should be noted that lack of previous research related to the objectives of this work limit comparing the results with previous findings. Therefore, the findings reported here are discussed with respect to general theory of production and remanufacturing.

\section{The effects of customer-stream used-products inter-arrival times on the remanufacturing cycle-time}

Figure 2 shows the effects of customer-stream used-products inter-arrival times on remanufacturing cycle-time for three different resource policies. As shown in Figure 2, 
for all three resource policies, remanufacturing cycle-time decreases as the inter-arrival times for customer-stream used-products becomes longer. For these resource policies, when used-products are modelled to arrive frequently at inter-arrival time of expo (3) days (hence more quantities), the remanufacturing cycle-time is longer because more used-products compete for the resource. When the quantities of used-products are modelled to be limited, arriving at expo (7) days, the remanufacturing cycle-time is shorter because less used-products compete for the resource. As expected, in remanufacturing industry, regardless of the resource policies, high quantities of customers-stream used-products would require longer time to process these used-products. The finding that the relationship between customers-stream used-products inter-arrival times and remanufacturing cycle-times is not linear, suggest that a graphical method would be appropriate for predicting the remanufacturing cycle-time for a given inter-arrival time of customers-stream used-products. Results shown in Figure 2 also implies that at inter-arrival time of customer-stream used-products that is extremely infrequent (hence very low quantities of used-products) the remanufacturing cycle-time would be the same regardless of which resource policy is implemented.

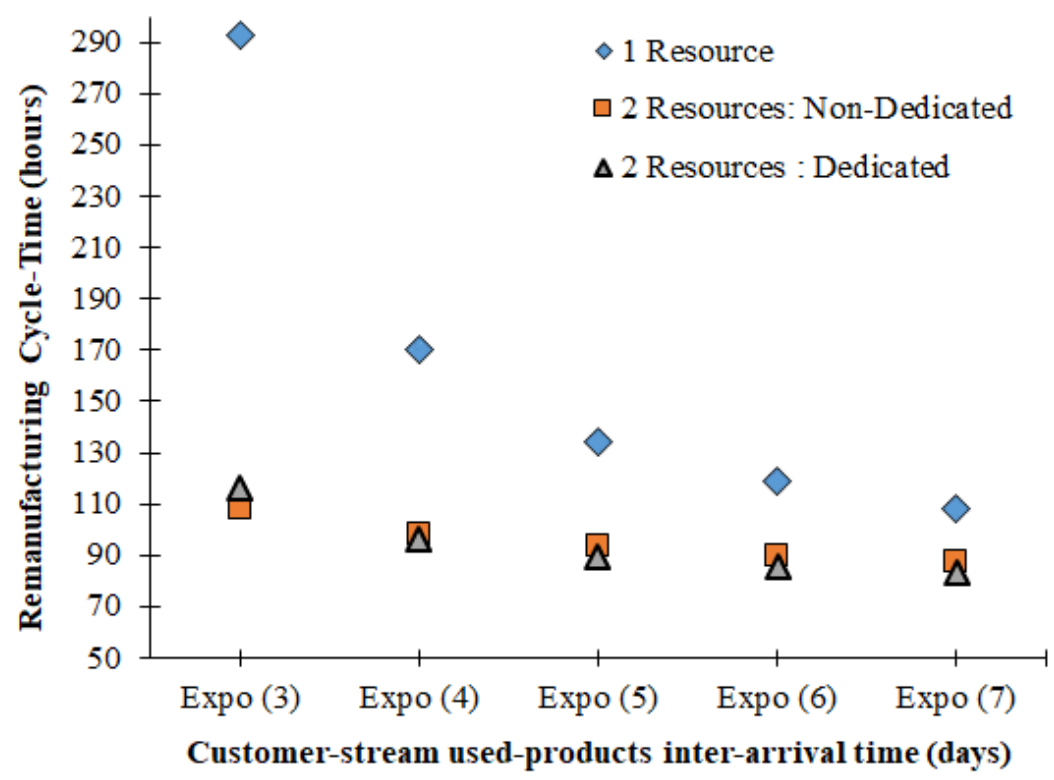

Figure 2. The effects of customer-stream used-products inter-arrival times on remanufacturing cycle-time

Policy 1 with one remanufacturing resource resulted in the longest remanufacturing cycle-time compared to the other two policies. As expected, when more resources are available (Policy $2 \& 3$ ), remanufacturing process takes place at a faster rate because used-products do not compete for the resource, thus resulting in shorter remanufacturing cycle-time. Between Policy 2 and Policy 3, there is not much difference in the remanufacturing cycle-time under all used-products inter-arrival times. This could be that the inter-arrival times of used-products are uncertain (modelled using exponential distribution. When used-products inter-arrival times are uncertain, then the quantities are also uncertain. Therefore, for Policy 2 \& Policy 3 (both with more resources), the 
remanufacturing cycle-times are not much different. This finding suggest that allocating more and dedicated resources might not always be beneficial for remanufacturing activities.

Figure 2 also shows that at frequent inter-arrival time (Expo (3) days), having more resources (Policy $2 \& 3$ ) resulted in a bigger reduction in the remanufacturing cycle-time when compared to Policy 1 . As expected, having more resources (Policy $2 \&$ 3 ) would lead to shorter remanufacturing cycle-time compared to limited resource (Policy 1. This agrees with the general production theories, where the benefit of allocating more resources would be significant at high volume of materials to be processed.

The above findings suggest that regardless of the resource policies, the remanufacturing cycle-time increases as the quantities of used-products becomes high at frequent inter-arrival times. This agrees with the general production theories where production cycle-time increases as the materials to be processed increases. A policy with more resources for remanufacturing leads to a shorter remanufacturing cycle-time, which also agrees with the production theories where allocating more resources to process materials lead to a shorter processing time. The reduction in remanufacturing cycle-time is greater at high used-products quantities. Nevertheless, more and dedicated resources for remanufacturing do not necessarily resulted further reduction in remanufacturing cycle-time compare to more and non-dedicated resource.

\section{The effects of third-party-stream used-products inter-arrival times on the remanufacturing cycle-time}

Figure 3 shows the effects of third-party-stream used-products inter-arrival times on remanufacturing cycle-time for three different resource policies. As seen in Figure 3, for Policy 1 the remanufacturing cycle-time decreases as used-products inter-arrival times becomes infrequent (hence low quantities). When used-products quantities are high at inter-arrival time of constant (3) days, remanufacturing cycle-time is longer because more used-products compete for the resource. As used-products quantities became low at inter-arrival time of constant (7) days, remanufacturing cycle-time is shorter because less used-products compete for the resource. As expected, high quantities of third-party-stream used-products need longer time to remanufacture. This agrees with the production theories that processing time would be longer as more materials need to be processed. Similarly, the non-linear relationship between third-party stream used-products inter-arrival times and remanufacturing cycle times, implies that a graphical method would be appropriate for predicting the remanufacturing cycle-time for a given inter-arrival time of third-party-stream used-products. Results shown in Figure 3 also implies that at inter-arrival time of third-party used-products that is extremely infrequent (hence very low quantities of used-products) the remanufacturing cycle-time would be the same regardless of which resource policy is implemented.

Comparing the three policies, Policy 1 with one remanufacturing resource, resulted in the longest remanufacturing cycle-time. When more resources are available (Policy $2 \& 3$ ), remanufacturing process takes place at a faster rate because used-products do not compete for the resource. Figure 3 also illustrates that the remanufacturing cycle-times for Policy $2 \& 3$ are not affected by the used-products inter-arrival times. Detail analysis shows that the remanufacturing cycle-time for Policy 2 decreases slightly from 96 hours (at constant (3) days) to 92 hours (at constant (7) days). As for Policy 3, the remanufacturing cycle-time increases slightly from 88 hours (at constant (3) days) to 
92 hours (at constant (7) days). Perhaps under the range of conditions (constant (3) to constant (7)) analysed in this study, the quantities of third-party-stream used-product are not high enough to result in a big reduction of remanufacturing cycle-time even when more resources are available for remanufacturing. This finding also suggest that allocating more and dedicated resources might not always be beneficial for remanufacturing activities.

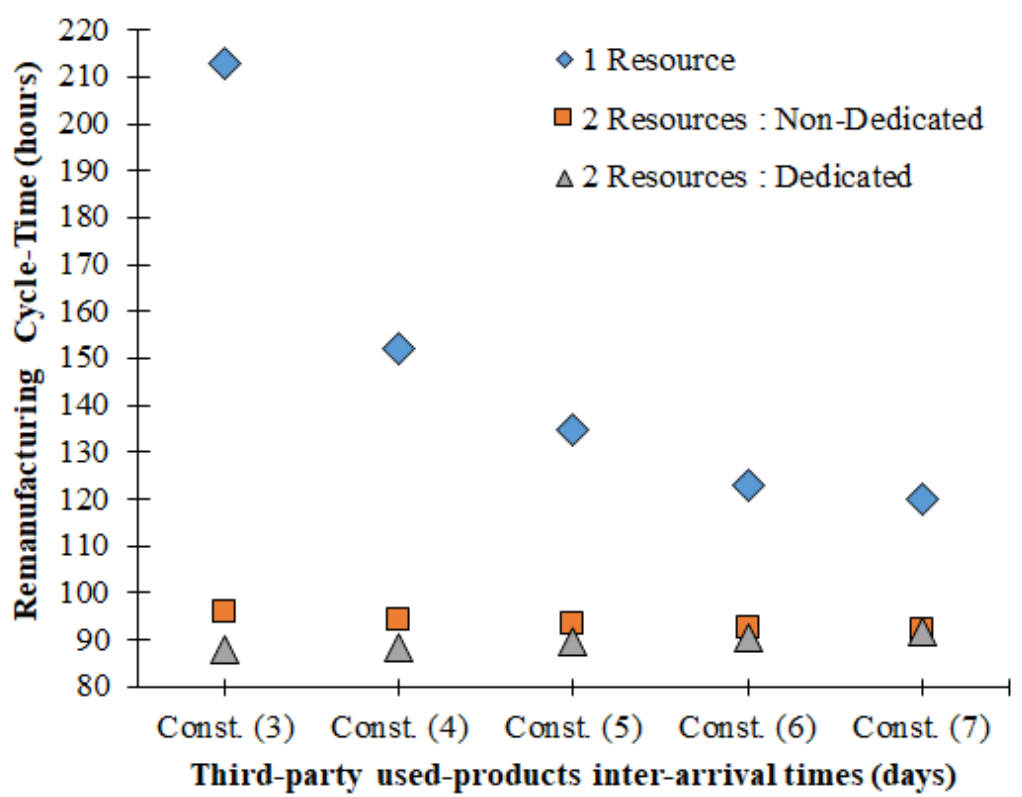

Figure 3. The effects of third-party stream used-products inter-arrival times on remanufacturing cycle-time.

Comparing Policy $2 \& 3$, there is not much difference in the remanufacturing cycle-time under all of the third-party used-products inter-arrival times. Probably, even though the inter-arrival times of used-products are certain (modelled using constant distribution), the quantity is still low because it is modelled as arriving one unit at a time. Thus, when the quantity of third-party-stream used-products is low, the remanufacturing cycle-times are not much different for Policy 2 \& Policy 3 (both with more resources).

Compared to Policy 1 , Policy $2 \& 3$ resulted in a big reduction in remanufacturing cycle-time at high quantities of used-products (i.e. at inter-arrival time of constant (3) days). More resources for remanufacturing leads to shorter remanufacturing cycle-time compared to limited resource. As anticipated, limited resource would result in longer remanufacturing cycle-time compared to more resources. Therefore, there is a big reduction in remanufacturing cycle-time between more and limited resource, this reduction is much greater at high quantities of third-party stream used-products. This agrees with the production theories, the benefit of allocating more resources would be significant at high volume of materials to be processed.

The above findings suggest that the quantities of third-party used-products greatly affect the remanufacturing cycle-time; where high quantities of used-products at frequent inter-arrival time resulted in longer remanufacturing cycle-time. This also agrees with the production theories that more materials would need more time to process. Moreover, the different number of resources also affect the remanufacturing cycle-time; where a policy with more resources resulted in a shorter remanufacturing cycle-time. More 
resources specifically dedicated to remanufacture each stream of used-products do not necessarily further reduce the remanufacturing cycle-time. Also the benefits of greater reduction in remanufacturing cycle-time occurs at high quantities of third-party stream used-products.

\section{The effects of used-products mix on the remanufacturing cycle-time}

Figure 4 shows the effects of used-products mix (modelled in terms of percentage) on remanufacturing cycle-time for three different resource policies. For example, a used-products mix of $20 \% \mathrm{C}-80 \% \mathrm{~T}$ indicates that $20 \%$ of the used-products are from the customers-stream and the rest $80 \%$ are from the third-party-stream. As depicted in Figure 4 , for all three policies, the remanufacturing cycle-time increases as the percentage of customer-stream used-products increases. As stated earlier, the inter-arrival times (hence quantities) of customer-stream used-products are modelled as uncertain (exponential distribution), therefore, when the percentage of customer-stream used-products becomes high, the remanufacturing cycle-time would become much longer because remanufacturing process has to be suspended while waiting for the incoming used-products. This shows that the customers-stream used-products would have a greater effect on remanufacturing cycle-time than the third-party-stream used-products. Results shown in Figure 4 also suggest that there is a percentage of used-products mix at which the remanufacturing cycle-time would be the same 9at low percentage of customer-stream used-products) regardless of the resource policies implemented.

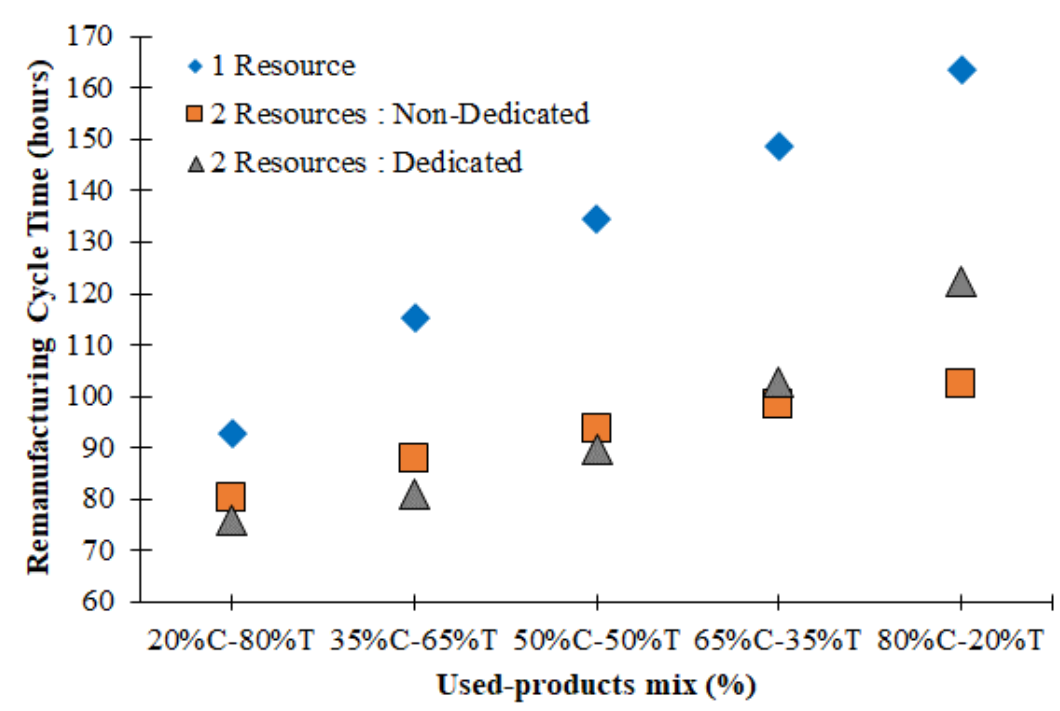

Figure 4. The effects of used-products mix on remanufacturing cycle-time

Amongst the three resource policies, Policy 1 with only one remanufacturing resource, resulted in the longest remanufacturing cycle-time compare to Policy $2 \& 3$. As expected, when resource is limited (Policy 1), remanufacturing process takes place at a slower rate because used-products have to compete for the resource, thus resulting in longer average remanufacturing cycle-time. Figure 4 also shows that Policy 3 (more and dedicated resources) resulted in the shortest remanufacturing cycle-time when the customers-stream used-products percentage is less than 58\%. As stated, the inter-arrival times (hence quantities) of third-party-stream used-products are modelled as certain 
(constant distribution), thus, when the percentage is high $(80 \%, 65 \%)$, having more and dedicated resources would result in faster remanufacturing process. This suggest that the benefits of more and dedicated resources (Policy 3 ) to reduce remanufacturing cycle-time would be significant at high volume of third-party-stream used-products.

When the percentage of third-party-stream used-products becomes low (below than $42 \%$ ) and the percentage of customer-stream used-products becomes higher (above $58 \%$ ), more and dedicated resource do not necessarily lead to the shortest remanufacturing cycle-time; in fact, Policy 2 yields the shortest remanufacturing cycle-time. Allocating dedicated resources to remanufacture each stream of used-products means that remanufacturing process has to be suspended while waiting for the incoming specific stream of used-products. Detail analysis using the process analyzer of the Arena simulation platform shows that between Policy $2 \& 3$, the remanufacturing cycle-time is significantly different. This suggest that Policy 3 is better at reducing the remanufacturing cycle-time when the percentage of customer-stream used-products is below 58\%; while Policy 2 would be better at reducing the remanufacturing cycle-time when the percentage of customer-stream used-products is more than $58 \%$. This clearly shows that the percentage of used-products mix affect the benefit of allocating more and dedicated resources; the benefit of Policy 3 would be more significant when the percentage of customer-stream used-products is below 58\%. This suggest that depending on the percentage of used-products mix, remanufacturing company could always switch between implementing Policy 2 and Policy 3.

Figure 4 also illustrates that compared to Policy 1, Policy 2 resulted in a big reduction in remanufacturing cycle-time at used-products mix of $80 \% \mathrm{C}-20 \% \mathrm{~T}$. More resources for remanufacturing leads to shorter remanufacturing cycle-time compared to limited resource. As expected, limited remanufacturing resource leads to longer remanufacturing cycle-time compared to more resources. Thus, there is a big reduction in remanufacturing cycle-time when the used-products mix has high percentage of customer-stream used-products. This suggests that the percentage of customers- stream used-products in the used-products mix influence the benefits incurred from using more resources to reduce the remanufacturing cycle time.

The findings suggest that used-products mix affect the remanufacturing cycle-time; high percentage of customers-stream used-products in the mix greatly affects the remanufacturing cycle-time. The different resource policies also affect the remanufacturing cycle time; more resources definitely reduce the remanufacturing cycle time. The biggest reduction would be observed at higher percentage of customers-stream used-products in the mix. Also, implementing more and dedicated resources would be significantly beneficial for a range of used-products mix percentage.

\section{Comparisons of different remanufacturing resource policies}

Table 2 shows the results of comparing the different remanufacturing resource policies. As shown in Table 2, under all operating conditions tabulated in Table 1, Policy 2 with more and non-dedicated resources to remanufacture either one of the used-products stream significantly reduce the remanufacturing cycle-time compared to Policy 1 . This finding clearly shows that implementing more resources significantly reduce the remanufacturing cycle time compare to implementing one resource. 
Similarly, Policy 3, with more and dedicated resources to remanufacture each stream of used-products significantly reduce the remanufacturing cycle-time compared to Policy 1. Thus, Policy 3 leads to remanufacturing cycle-time that is significantly shorter than the remanufacturing cycle-time of Policy 1. This result also shows that implementing more and dedicated resources significantly reduce the remanufacturing cycle time compared to implementing one resource.

Comparing Policy 3 and 2, there are several operating conditions (Case 1, 2, 3, 4, $5,6,8,14,15,16,18)$ under which Policy 3 significantly reduce the remanufacturing cycle-time compared to Policy 2 . This finding shows that having more and dedicated resources would only significantly reduce the remanufacturing cycle time under certain operating conditions. Table 3 also shows that there are several operating conditions (marked by **) under which Policy 3 significantly increase the remanufacturing cycle-time compared to Policy 2. Thus, it must be noted that there are situations when implementing more and dedicated resources would significantly increase the remanufacturing cycle time, this occurs when the percentage of customers-stream used-products in the mix is more than $50 \%$.

These findings clearly suggest that implementing more resources for remanufacturing would significantly reduce the remanufacturing cycle-time. However, specifically dedicating more resources for remanufacturing each stream of used-products would only significantly reduce the remanufacturing cycle-time under certain conditions.

Table 2. Comparison of different remanufacturing resource policies

\begin{tabular}{|c|c|c|c|c|c|c|c|}
\hline \multirow[t]{2}{*}{$\begin{array}{l}\text { No } \\
\text {. }\end{array}$} & \multirow{2}{*}{$\begin{array}{l}\text { Customer } \\
\text { s-stream } \\
\text { used-prod } \\
\text { ucts } \\
\text { inter-arri } \\
\text { val time }\end{array}$} & \multirow{2}{*}{$\begin{array}{l}\text { Third-par } \\
\text { ty-stream } \\
\text { used-prod } \\
\text { ucts } \\
\text { inter-arri } \\
\text { val time }\end{array}$} & \multirow[t]{2}{*}{$\begin{array}{l}\text { Used-pro } \\
\text { ducts mix }\end{array}$} & \multirow{2}{*}{$\begin{array}{l}\text { Customer } \\
\text { s-stream } \\
\text { used-prod } \\
\text { ucts } \\
\text { overall } \\
\text { repair } \\
\text { time }\end{array}$} & \multicolumn{3}{|c|}{$\begin{array}{c}\text { Differences in average } \\
\text { remanufacturing } \\
\text { cycle-time }\end{array}$} \\
\hline & & & & & $\begin{array}{l}\text { Policy } \\
2 \text { vs } \\
\text { Policy } \\
1\end{array}$ & $\begin{array}{l}\text { Policy } \\
3 \text { vs } \\
\text { Policy } \\
1\end{array}$ & $\begin{array}{l}\text { Policy } \\
3 \text { vs } \\
\text { Policy } \\
2\end{array}$ \\
\hline 1 & $\begin{array}{c}\text { Expo (4) } \\
\text { days }\end{array}$ & $\begin{array}{c}\text { Const. (3) } \\
\text { days }\end{array}$ & $\begin{array}{c}20 \% \mathrm{C}-80 \\
\% \mathrm{~T}\end{array}$ & Unif $(3,4)$ & $*$ & $*$ & $*$ \\
\hline 2 & $\begin{array}{c}\text { Expo (7) } \\
\text { days }\end{array}$ & $\begin{array}{c}\text { Const. (3) } \\
\text { days }\end{array}$ & $\begin{array}{c}20 \% \mathrm{C}-80 \\
\% \mathrm{~T}\end{array}$ & Unif $(3,4)$ & $*$ & $*$ & $*$ \\
\hline 3 & $\begin{array}{c}\text { Expo (4) } \\
\text { days }\end{array}$ & $\begin{array}{c}\text { Const. (7) } \\
\text { days }\end{array}$ & $\begin{array}{c}20 \% \mathrm{C}-80 \\
\% \mathrm{~T}\end{array}$ & Unif $(3,4)$ & $*$ & $*$ & $*$ \\
\hline 4 & $\begin{array}{c}\text { Expo (7) } \\
\text { days }\end{array}$ & $\begin{array}{c}\text { Const. (7) } \\
\text { days }\end{array}$ & $\begin{array}{c}20 \% \mathrm{C}-80 \\
\% \mathrm{~T}\end{array}$ & Unif $(3,4)$ & $*$ & $*$ & $*$ \\
\hline 5 & $\begin{array}{c}\text { Expo (4) } \\
\text { days }\end{array}$ & $\begin{array}{c}\text { Const. (3) } \\
\text { days }\end{array}$ & $\begin{array}{c}50 \% \mathrm{C}-50 \\
\% \mathrm{~T}\end{array}$ & Unif $(3,4)$ & $*$ & $*$ & $*$ \\
\hline 6 & $\begin{array}{c}\text { Expo (7) } \\
\text { days }\end{array}$ & $\begin{array}{c}\text { Const. (3) } \\
\text { days }\end{array}$ & $\begin{array}{c}50 \% \mathrm{C}-50 \\
\% \mathrm{~T}\end{array}$ & Unif $(3,4)$ & $*$ & $*$ & $*$ \\
\hline 7 & $\begin{array}{c}\text { Expo (4) } \\
\text { days }\end{array}$ & $\begin{array}{c}\text { Const. (7) } \\
\text { days }\end{array}$ & $\begin{array}{c}50 \% \mathrm{C}-50 \\
\% \mathrm{~T}\end{array}$ & Unif $(3,4)$ & $*$ & $*$ & $* *$ \\
\hline 8 & $\begin{array}{c}\text { Expo }(7) \\
\text { days }\end{array}$ & $\begin{array}{c}\text { Const. (7) } \\
\text { days }\end{array}$ & $\begin{array}{c}50 \% \mathrm{C}-50 \\
\% \mathrm{~T}\end{array}$ & Unif $(3,4)$ & $*$ & $*$ & $*$ \\
\hline 9 & $\begin{array}{c}\text { Expo (4) } \\
\text { days }\end{array}$ & $\begin{array}{c}\text { Const. (3) } \\
\text { days }\end{array}$ & $\begin{array}{c}80 \% \mathrm{C}-20 \\
\% \mathrm{~T}\end{array}$ & Unif $(3,4)$ & $*$ & $*$ & $* *$ \\
\hline
\end{tabular}




\begin{tabular}{|c|c|c|c|c|c|c|c|}
\hline 10 & $\begin{array}{c}\text { Expo (7) } \\
\text { days }\end{array}$ & $\begin{array}{c}\text { Const. (3) } \\
\text { days }\end{array}$ & $\begin{array}{c}80 \% \mathrm{C}-20 \\
\% \mathrm{~T}\end{array}$ & Unif $(3,4)$ & $*$ & $*$ & $* *$ \\
\hline 11 & $\begin{array}{c}\text { Expo (4) } \\
\text { days }\end{array}$ & $\begin{array}{c}\text { Const. (7) } \\
\text { days }\end{array}$ & $\begin{array}{c}80 \% \mathrm{C}-20 \\
\% \mathrm{~T}\end{array}$ & Unif $(3,4)$ & $*$ & $*$ & $* *$ \\
\hline 12 & $\begin{array}{c}\text { Expo (7) } \\
\text { days }\end{array}$ & $\begin{array}{c}\text { Const. (7) } \\
\text { days }\end{array}$ & $\begin{array}{c}80 \% \mathrm{C}-20 \\
\% \mathrm{~T}\end{array}$ & Unif $(3,4)$ & $*$ & $*$ & $* *$ \\
\hline 13 & $\begin{array}{c}\text { Expo (4) } \\
\text { days }\end{array}$ & $\begin{array}{c}\text { Const. (3) } \\
\text { days }\end{array}$ & $\begin{array}{c}20 \% \mathrm{C}-80 \\
\% \mathrm{~T}\end{array}$ & Unif $(7,8)$ & $*$ & $*$ & $*$ \\
\hline 14 & $\begin{array}{c}\text { Expo }(7) \\
\text { days }\end{array}$ & $\begin{array}{c}\text { Const. (3) } \\
\text { days }\end{array}$ & $\begin{array}{c}20 \% \mathrm{C}-80 \\
\% \mathrm{~T}\end{array}$ & Unif $(7,8)$ & $*$ & $*$ & $*$ \\
\hline 15 & $\begin{array}{c}\text { Expo (4) } \\
\text { days }\end{array}$ & $\begin{array}{c}\text { Const. (7) } \\
\text { days }\end{array}$ & $\begin{array}{c}20 \% \mathrm{C}-80 \\
\% \mathrm{~T}\end{array}$ & Unif $(7,8)$ & $*$ & $*$ & $*$ \\
\hline 16 & $\begin{array}{c}\text { Expo (7) } \\
\text { days }\end{array}$ & $\begin{array}{c}\text { Const. (7) } \\
\text { days }\end{array}$ & $\begin{array}{c}20 \% \mathrm{C}-80 \\
\% \mathrm{~T}\end{array}$ & Unif $(7,8)$ & $*$ & $*$ & $*$ \\
\hline 17 & $\begin{array}{c}\text { Expo (4) } \\
\text { days }\end{array}$ & $\begin{array}{c}\text { Const. (3) } \\
\text { days }\end{array}$ & $\begin{array}{c}50 \% \mathrm{C}-50 \\
\% \mathrm{~T}\end{array}$ & Unif $(7,8)$ & $*$ & $*$ & $* *$ \\
\hline 18 & $\begin{array}{c}\text { Expo (7) } \\
\text { days }\end{array}$ & $\begin{array}{c}\text { Const. (3) } \\
\text { days }\end{array}$ & $\begin{array}{c}50 \% \mathrm{C}-50 \\
\% \mathrm{~T}\end{array}$ & Unif $(7,8)$ & $*$ & $*$ & $*$ \\
\hline 19 & $\begin{array}{c}\text { Expo (4) } \\
\text { days }\end{array}$ & $\begin{array}{c}\text { Const. (7) } \\
\text { days }\end{array}$ & $\begin{array}{c}50 \% \mathrm{C}-50 \\
\% \mathrm{~T}\end{array}$ & Unif $(7,8)$ & $*$ & $*$ & $* *$ \\
\hline 20 & $\begin{array}{c}\text { Expo (7) } \\
\text { days }\end{array}$ & $\begin{array}{c}\text { Const. (7) } \\
\text { days }\end{array}$ & $\begin{array}{c}50 \% \mathrm{C}-50 \\
\% \mathrm{~T}\end{array}$ & Unif $(7,8)$ & $*$ & $*$ & $* *$ \\
\hline 21 & $\begin{array}{c}\text { Expo (4) } \\
\text { days }\end{array}$ & $\begin{array}{c}\text { Const. (3) } \\
\text { days }\end{array}$ & $\begin{array}{c}80 \% \mathrm{C}-20 \\
\% \mathrm{~T}\end{array}$ & Unif $(7,8)$ & $*$ & $*$ & $* *$ \\
\hline 22 & $\begin{array}{c}\text { Expo (7) } \\
\text { days }\end{array}$ & $\begin{array}{c}\text { Const. (3) } \\
\text { days }\end{array}$ & $\begin{array}{c}80 \% \mathrm{C}-20 \\
\% \mathrm{~T}\end{array}$ & Unif $(7,8)$ & $*$ & $*$ & $* *$ \\
\hline 23 & $\begin{array}{c}\text { Expo (4) } \\
\text { days }\end{array}$ & $\begin{array}{c}\text { Const. (7) } \\
\text { days }\end{array}$ & $\begin{array}{c}80 \% \mathrm{C}-20 \\
\% \mathrm{~T}\end{array}$ & Unif $(7,8)$ & $*$ & $*$ & $* *$ \\
\hline 24 & $\begin{array}{c}\text { Expo (7) } \\
\text { days }\end{array}$ & $\begin{array}{c}\text { Const. (7) } \\
\text { days }\end{array}$ & $\begin{array}{c}80 \% \mathrm{C}-20 \\
\% \mathrm{~T}\end{array}$ & Unif $(7,8)$ & $*$ & $*$ & $* *$ \\
\hline
\end{tabular}

*significantly reduce the remanufacturing cycle-time

**significantly increase the remanufacturing cycle-time

\section{CONCLUSIONS}

Production planning activities in remanufacturing systems are complicated due to the presence of several unique characteristics. Despite numerous research on remanufacturing, there is limited research that focus on the effects of uncertain quantities and quality conditions of used-products acquired from the customers' and/or third-party stream on the performance of remanufacturing system using simulation technique. Thus, this article has study the problem of uncertain quantities and qualities of used-products from the customers and/or third-party stream under three different resource policies.

Consequently, the findings of this work are significant because it shows that the performance of a remanufacturing system is affected by (i) the uncertain quantities of used-products, (ii) the different sources for obtaining used-products, (iii) the percentage of used-products mix (iv) the different remanufacturing resource policies. This work has also made contributions to the literature on remanufacturing by developing a simulation 
model that considers (i) the uncertain quantities and quality conditions of used-products, (ii) the different sources for obtaining used-products, (iii) the different remanufacturing resources.

The simulation model could be enhanced to consider other complicating characteristics of remanufacturing environment. Thus, the future direction of this work is to enhance the simulation model to consider different distributions for modelling the uncertain quality conditions of used-products from the two sources. In this work, the uncertain quality conditions of used-products from the two sources are modelled in terms of uncertain overall repair times. The third-party-stream used-products are assumed to be in better quality conditions compared to the customers-stream used-products, thus the overall repair time is shorter than the overall repair time for used-products from the customers-stream.

The simulation model would also be enhanced to consider used-product inspection \& grading policies. This involves comparing several different inspection $\&$ grading policies in order to determine which policy is better under which operating conditions. Similar to normal manufacturing, there are two common production strategies for remanufacturing, namely remanufacture to order (RMTO) and remanufacture to stock (RMTS). Thus, for future works that consider different distributions for modelling uncertain quality conditions and different inspection \& grading policies, the simulation model would be enhanced to consider RMTO and RMTS strategies.

\section{ACKNOWLEDGMENT}

This work is supported by Universiti Malaysia Sarawak (UNIMAS) under the Small Grant Scheme Project [F02/S172)/1274/2015(09)].

\section{REFERENCES}

[1] Golinska-Dawson P, Kosacka M, Nowak A. The Survey on the Challenges of Organization of Automotive Component Remanufacturing in Small-sized Companies in Poland. In: Kachitvichyanukul V, Sethanan K, Golinska- Dawson P, editors. Toward Sustainable Operations of Supply Chain and Logistics Systems. Cham: Springer International Publishing; 2015. p. 241-252.

[2] Graham I, Goodall P, Peng Y, Palmer C, West A, Conway P, Mascolo JE, Dettmer FU. Performance measurement and KPIs for remanufacturing. Journal of Remanufacturing. 2015;5:10.

[3] Chaowanapong J, Jongwanich J, Ijomah W. The determinants of remanufacturing practices in developing countries: Evidence from Thai industries. Journal of Cleaner Production. 2018;170:369-378.

[4] Aydin R, Kwong CK, Ji P. A novel methodology for simultaneous consideration of remanufactured and new products in product line design. International Journal of Production Economics. 2015;169:127-140.

[5] Chaowanapong J, Jongwanich J. Sustainable Manufacturing for Thai Firms: A Case Study of Remanufactured Photocopiers. Cham: Springer International Publishing; 2017. p. 245-256.

[6] Oh Y, Behdad S. Simultaneous reassembly and procurement planning in assemble-to-order remanufacturing systems. International Journal of Production Economics. 2017;184:168-178. 
[7] Andrew-Munot M, Ibrahim RN. Development and analysis of mathematical and simulation models of decision-making tools for remanufacturing. Production Planning \& Control. 2013;24:1081-1100.

[8] Butzer S, Kemp D, Steinhilper R, Schötz S. Identification of approaches for remanufacturing 4.0. 2016 IEEE European Technology and Engineering Management Summit (E-TEMS)2016. p. 1-6.

[9] Golinska- Dawson P, Kosacka M, Nowak A. Automotive Parts Remanufacturing-Experience of Polish Small Companies. CMUJ NS Special Issue on Logistics and Supply Chain 2015;14:415-430.

[10] Zhang R, Ong SK, Nee AYC. A simulation-based genetic algorithm approach for remanufacturing process planning and scheduling. Applied Soft Computing. 2015;37:521-532.

[11] Zikopoulos C. Remanufacturing lotsizing with stochastic lead-time resulting from stochastic quality of returns. International Journal of Production Research. 2017;55:1565-1587.

[12] Seifert S, Burtzer S, Westermann H, Steinhilper R. Managing complexity in Remanufacturing. . In Proc World Congress on Engineering, UK2013.

[13] Andrew-Munot M, Ibrahim RN. Remanufacturing process and its challenges. Journal of Mechanical Engineering and Sciences,. 2013;4:488-495.

[14] Junior ML, Filho MG. Production planning and control for remanufacturing: literature review and analysis. Production Planning \& Control. 2012;23:419-435.

[15] Morgan SD, Gagnon RJ. A systematic literature review of remanufacturing scheduling. International Journal of Production Research. 2013;51:4853-4879.

[16] Matsumoto M, Yang S, Martinsen K, Kainuma Y. Trends and research challenges in remanufacturing. International Journal of Precision Engineering and Manufacturing-Green Technology. 2016;3:129-142.

[17] Priyono A, Ijomah W, Bititci U. Disassembly for remanufacturing: A systematic literature review, new model development and future research needs. Journal of Industrial Engineering and Management. 2016;9:899-932.

[18] Lage Junior M, Godinho Filho M. Production planning and control for remanufacturing: exploring characteristics and difficulties with case studies. Production Planning \& Control. 2016;27:212-225.

[19] Teunter RH, Flapper SDP. Optimal core acquisition and remanufacturing policies under uncertain core quality fractions. European Journal of Operational Research. 2011;210:241-248.

[20] Jin X, Ni J, Koren Y. Optimal control of reassembly with variable quality returns in a product remanufacturing system. CIRP Annals. 2011;60:25-28.

[21] Karamouzian A, Teimoury E, Modarres M. A model for admission control of returned products in a remanufacturing facility using queuing theory. The International Journal of Advanced Manufacturing Technology. 2011;54:403-412.

[22] Iwao M, Kusukawa M. Optimal production planning for remanufacturing with uncertainty in quality of returns and classification error in quality grading. Proceedings of the Asia Pacific Industrial Engineering \& Management Systems Conference Osaka2012.

[23] Tao Z, Zhou SX, Tang CS. Managing a Remanufacturing System with Random Yield: Properties, Observations, and Heuristics. Production and Operations Management. 2012;21:797-813. 
[24] Mezghani M, Loukil T. Remanufacturing planning with imprecise quality inputs through the goal programming and the satisfaction functions. International Journal of Multicriteria Decision Making. 2012;2:379-390.

[25] Robotis A, Boyaci T, Verter V. Investing in reusability of products of uncertain remanufacturing cost: The role of inspection capabilities. International Journal of Production Economics. 2012;140:385-395.

[26] Zikopoulos C. Remanufacturing lot-sizing under alternative perceptions of returned units' quality. International Journal of Business Science \& Applied Management. 2012;7:12-22.

[27] X J, J HS, J N, G X. Assembly Strategies for Remanufacturing Systems With Variable Quality Returns. IEEE Transactions on Automation Science and Engineering. 2013;10:76-85.

[28] Karamouzian A, Naini SGJ, Mazdeh MM. Management of returned products to a remanufacturing facility considering arrival uncertainty and priority processing. International Journal of Operational Research. 2014;20:331-340.

[29] Wei S, Tang O, Sundin E. Core (product) Acquisition Management for remanufacturing: a review. Journal of Remanufacturing. 2015;5:4.

[30] Alqahtani AY, Gupta SM, Nakashima K. Performance Analysis of Advanced Remanufacture-To-Order,Disassembly-To-Order and Refurbishment-To-Order System. Innovation and Supply Chain Management. 2014;8:140-149.

[31] Yang CH, Wang J, Ji P. Optimal acquisition policy in remanufacturing under general core quality distributions. International Journal of Production Research. 2015;53:1425-1438.

[32] Mashhadi AR, Esmaeilian B, Behdad S. Uncertainty Management in Remanufacturing Decisions: A Consideration of Uncertainties in Market Demand, Quantity, and Quality of Returns. ASCE-ASME Journal of Risk and Uncertainty in Engineering Systems, Part B: Mechanical Engineering. 2015;1:021007-021007-021008.

[33] Li X, Li Y, Cai X. On Core Sorting in RMTS and RMTO Systems: A Newsvendor Framework. Decision Sciences. 2016;47:60-93.

[34] Mutha A, Bansal S, Guide VDR. Managing demand uncertainty through core acquisition in remanufacturing. Production and Operations Management. 2016;25:1449-1464.

[35] Yang CH, Bao XY, Song C, Liu HB. Optimal acquisition policy in remanufacturing systems with quantity discount and carbon tax scheme. Tehnički vjesnik. 2016;23:1073-1081.

[36] Yang CH, Liu Hb, Ji P, Ma X. Optimal acquisition and remanufacturing policies for multi-product remanufacturing systems. Journal of Cleaner Production. 2016;135:1571-1579.

[37] Aydin R, Kwong CK, Geda MW, Okudan Kremer GE. Determining the optimal quantity and quality levels of used product returns for remanufacturing under multi-period and uncertain quality of returns. The International Journal of Advanced Manufacturing Technology. 2018;94:4401-4414.

[38] Gavidel SZ, Rickli JL. Quality assessment of used-products under uncertain age and usage conditions. International Journal of Production Research. 2017;55:7153-7167.

[39] Gavidel SZ, Rickli JL. Remanufacturing cost analysis under uncertain core quality and return conditions: extreme and non-extreme scenarios. arXiv preprint arXiv:180110497. 2018. 
[40] Zhou J, Deng Q, Li T. Optimal acquisition and remanufacturing policies considering the effect of quality uncertainty on carbon emissions. Journal of Cleaner Production. 2018;186:180-190.

[41] Kelton W, Sadowski R, Zupick N. Simulation with Arena. 6th ed. Singapore McGraw-Hill; 2015.

[42] Lari O, Singh H. Basics of Modelling and Simulation 1ed: S. K. Kataria \& Sons; 2015.

[43] Ab Rashid MFF, Mohamed NN, Rose AM, Kor KY. Simulation study of a vehicle production line for productivity improvement. Journal of Mechanical Engineering and Sciences,. 2015;8:1283-1292.

[44] Automation R. Arena simulation software. 15 ed.

[45] Shah P, Gosavi A, Nagi R. A machine learning approach to optimise the usage of recycled material in a remanufacturing environment. International Journal of Production Research. 2010;48:933-955. 